\title{
Newly published studies on satiety benefits of Korean pine nut oil (PinnoThin ${ }^{\mathrm{TM}}$ )
}

\author{
Chryssanthi L. STYLIANOPOULOS ${ }^{1}$ \\ Hiskias G. KEIZER ${ }^{1,2}$ \\ ${ }^{1}$ Lipid Nutrition, BV, \\ Nutrition \& Toxicology Department \\ ${ }^{2}$ Lipid Nutrition, BV, Hogeweg 1, P.O. Box 4. \\ 1520AA Wormerveer, The Netherlands \\ <hiskias.keizer@lipidnutrition.com>
}

\begin{abstract}
A Korean pine nut oil product, PinnoThin' ${ }^{T M}$, has been shown to trigger the release of the satiety gut hormone cholecystokinin (CCK) in vitro. Recently published randomized, placebo-controlled double-blind crossover clinical trials have investigated the effects of PinnoThin ${ }^{T M}$ on satiety markers. $A$ clinical trial in 18 overweight postmenopausal women, studied the effects of PinnoThin ${ }^{T M}$ free fatty acid (FFA) and triglyceride (TC) versus placebo (olive oil) on CCK and glucagon peptide-1 (GLP-1) release and appetite sensations. PinnoThin ${ }^{T M}$ FFA and TG were shown to have significant effects on CCK release, while PinnoThin ${ }^{T M}$ FFA had significant effects on GLP-1. Prospective food intake assessed by visual analogue scale (VAS) was significantly reduced 30 minutes after PinnoThin ${ }^{T M}$ FFA intake. Another study on 42 overweight young women investigated the effects of PinnoThin ${ }^{T M}$ FFA and different doses of PinnoThin ${ }^{T M}$ TG versus placebo (olive oil) on food intake, feeding behaviour and appetite. PinnoThin ${ }^{T M}$ FFA given 30 minutes prior to ad libitum buffet lunch significantly reduced food intake (grams) and tended to decrease energy intake ( $k c a l$ ) compared to placebo, while no compensation for the reduced intake was observed at ad libitum dinner. Since it was previously shown that PinnoThin ${ }^{T M}$ TC is normally hydrolyzed to PinnoThin ${ }^{T M}$ FFA, the differential results seen in the case of PinnoThin ${ }^{T M}$ FFA and TC are consistent with a delay in TG conversion to FFA. These studies suggest that PinnoThin ${ }^{T M}$ has satiating effects corresponding to increased release of satiety hormones CCK and GLP-1 and decrease in subsequent food intake.
\end{abstract}

Key words: satiety, satiation, fatty acids, triglyceride, CCK, cholecystokinin

tion in gastric motility and increase in gastric distension, resulting in feelings of fullness and inhibition of food intake [4]. TG hydrolysis is necessary for induction of CCK release, and inhibition of lipase action has been shown to markedly decrease CCK secretion $[8,13,14]$. Numerous studies have shown that exogenous CCK infusions reduce food intake and suppress appetite [11, 15-20]. CCK antagonists generally have the reverse effect on appetite and have been associated with weight gain in rodents [21, 22].

GLP-1 is also known to be a potent regulator of food intake. It has been shown that peripheral administration of GLP-1 reduces energy intake in a dose-dependent manner in both lean and overweight human subjects [23]. Much like CCK, GLP-1 is produced in response to the presence of fat in the gut lumen [24]. GLP-1 release leads to a delay in gastric emptying, early satiety and a decrease in food consumption, which serves as a negative feedback signal to limit the amount of food consumed [14, 23-26].

Korean pine nut oil consists mainly of long chain polyunsaturated fatty acids (PUFA) and has a uniquely high concentration of pinolenic acid. The fatty acid profile of Korean pine nut oil suggests a possible role on satiety hormone release. This role is in line with the available evidence showing an induction of satiety hormones and a consequent reduction of appetite after ingestion of long-chain PUFA [7, 13, 27]. This report summarizes data from previously published studies to support the role of Korean pine nut oil or PinnoThin ${ }^{\mathrm{TM}}$ on satiety. First, in vitro data are presented to demonstrate the stimulatory effect of PinnoThin ${ }^{\mathrm{TM}}$ on satiety hormones. Second, data from two human randomized double-blind placebo-controlled crossover trials are presented to show the effect of PinnoThin ${ }^{\mathrm{TM}}$ on satiety hormones in vivo, appetite sensations and food intake.

\section{Effects of PinnoThin TM FFA on CCK release in vitro}

Murine endocrine STC-1 cells were utilized in this study to investigate the capacity of Korean pine nut oil or PinnoThin ${ }^{\mathrm{TM}}$ to induce CCK compared to another type of pine nut (Italian pine nut) and common dietary fatty acids [28]. STC-1 cells secrete CCK in response to a number of stimuli and are a useful took for examining the pathways involved in CCK secretion [29]. As a result to this exposure, the increase in 


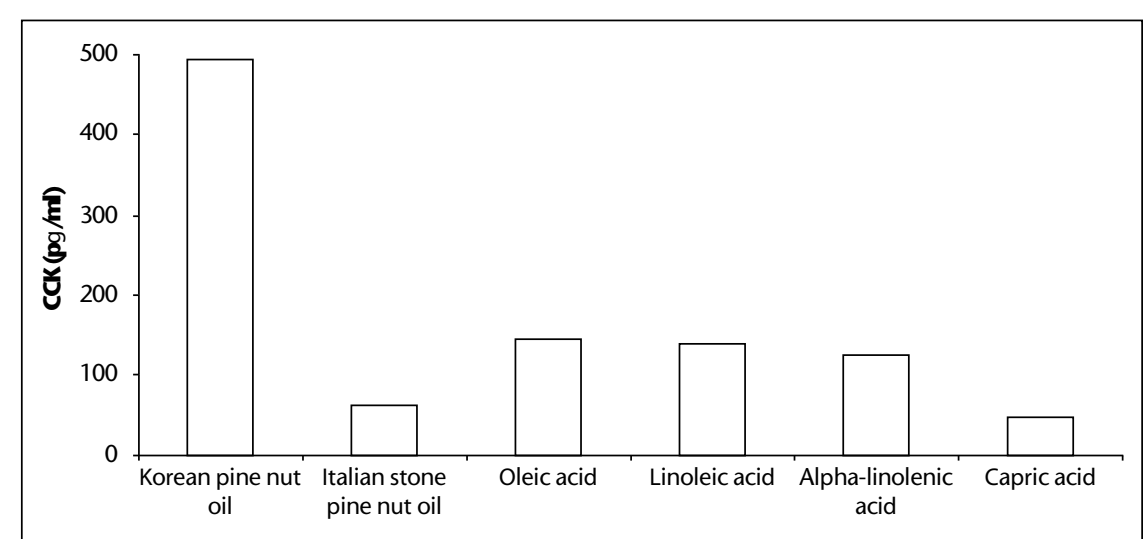

Figure 1. Free fatty acids from Korean pine nut oil (PinnoThin ${ }^{T M}$ ), Italian stone pine nut oil and the fatty acids oleic, linoleic, alpha-linolenic were compared with respect to CCK release from STC-1 cells after exposure for 1 hour to 50 $\mu \mathrm{M}$ of the fatty acids. Capric acid served as a negative control (adapted from [28]).
CCK release was measured (figure 1). Capric acid and Italian stone pine nut FFA produced only a small amount of CCK release $(46 \mathrm{pg} / \mathrm{mL}$ and $62 \mathrm{pg} / \mathrm{mL}$ respectively). Different dietary fatty acids, namely oleic, linoleic, and alphalinolenic, produced an intermediate CCK release $(145 \mathrm{pg} / \mathrm{mL}, \quad 138 \mathrm{pg} / \mathrm{mL}$ and $124 \mathrm{pg} / \mathrm{mL}$ respectively). Korean pine nut oil FFA produced by far the largest CCK release $(493 \mathrm{pg} / \mathrm{mL})$. The strong stimulating effect of Korean pine nut FFA in vitro prompted further investigation. It was of great interest to confirm the induction of CCK release by PinnoThin ${ }^{T M}$ in a human trial.

\section{Effects of PinnoThin ${ }^{\text {TM }}$ FFA and TG on gut satiety hormones and appetite sensations}

The effect of pine nut oil on CCK in humans was evaluated in a randomized, double blind, placebo-controlled, cross-over trial [28]. In this study, eighteen overweight, but otherwise healthy, post-menopausal women participated in this study. They were given a simple breakfast, consisting of two slices of white bread and marmalade, along with $3 \mathrm{G}$ PinnoThin ${ }^{\mathrm{TM}}$ FFA, 3G PinnoThin ${ }^{\mathrm{TM}}$ TG or 3G placebo (olive oil). Both CCK and GLP-1 release in the blood was measured 30, 60, 90, 120, 180 and 240 minutes after the start of the breakfast. During the same time period, subjective measures of appetite sensations were quantified using a $100 \mathrm{~mm}$ visual analogue scale (VAS). Each volunteer completed all three interventions (PinnoThin ${ }^{\mathrm{TM}}$ wash-out in-between.

CCK release was significantly higher after PinnoThin ${ }^{\mathrm{TM}}$ TG and FFA intake compared to placebo and (figure 2; $p<0.05$ ). The effect on CCK release became apparent after 60 minutes FFA, PinnoThin ${ }^{\mathrm{TM}}$ TG and placebo) with 1 week
When volunteers rated their prospective food consumption, which is a measure of how much food the volunteers believed they could consume, an effect of PinnoThin ${ }^{\mathrm{TM}}$ was observed. Prospective food consumption, calculated by VAS scores, tended to be lower after PinnoThin $^{\mathrm{TM}}$ TG consumption $(p=0.06)$ and was significantly lower 30 minutes after PinnoThin ${ }^{\text {TM }}$ FFA intake $(p<0.05)$.

In conclusion, this clinical trial showed that PinnoThin ${ }^{\mathrm{TM}}$ consumption is associated with increased release of the gut satiety hormones CCK and GLP-1 and may influence feelings of satiety by reducing prospective food intake.

\section{Effects of PinnoThin TM FFA and TC on food intake, feeding behaviour and appetite}

for the PinnoThin ${ }^{\mathrm{TM}}$ TG and after 30 minutes for the PinnoThin ${ }^{\text {TM }}$ FFA. The total CCK release for PinnoThin ${ }^{\text {TM }}$ TG was $22 \%$ higher compared to placebo and $60 \%$ higher for PinnoThin ${ }^{\mathrm{TM}}$ FFA $(p<0.05)$. GLP-1 release was significantly higher after PinnoThin ${ }^{\mathrm{TM}}$ FFA compared to placebo at 60 minutes $(p<0.05)$ (figure 3$)$. The total GLP-1 release for PinnoThin ${ }^{\mathrm{TM}}$ FFA was $25 \%$ higher than placebo $(p<0.05)$.

The effect of PinnoThin ${ }^{\mathrm{TM}}$ TG and FFA was evaluated in a randomized double-blinded placebo-controlled cross-over trial [30]. This trial included 42 overweight, but otherwise healthy women. The volunteers received a standard breakfast in the morning. Half an hour before lunch time, they were given $2,4,6 \mathrm{~g}$ of

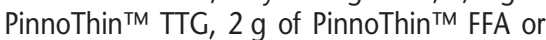

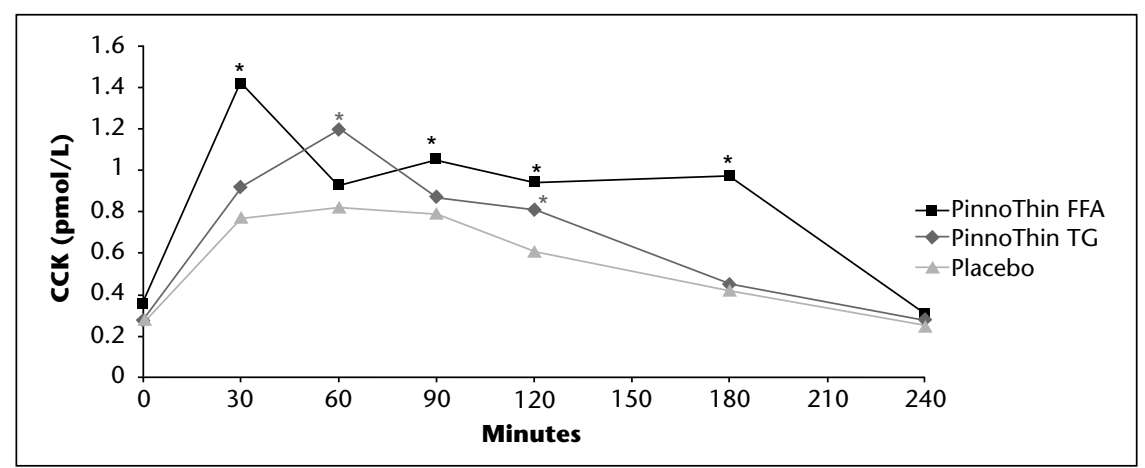

Figure 2. Four hour postprandial responses of CCK in 18 overweight women. Significant differences versus placebo $(p<0.05)$ indicated by * (adapted from [28]).

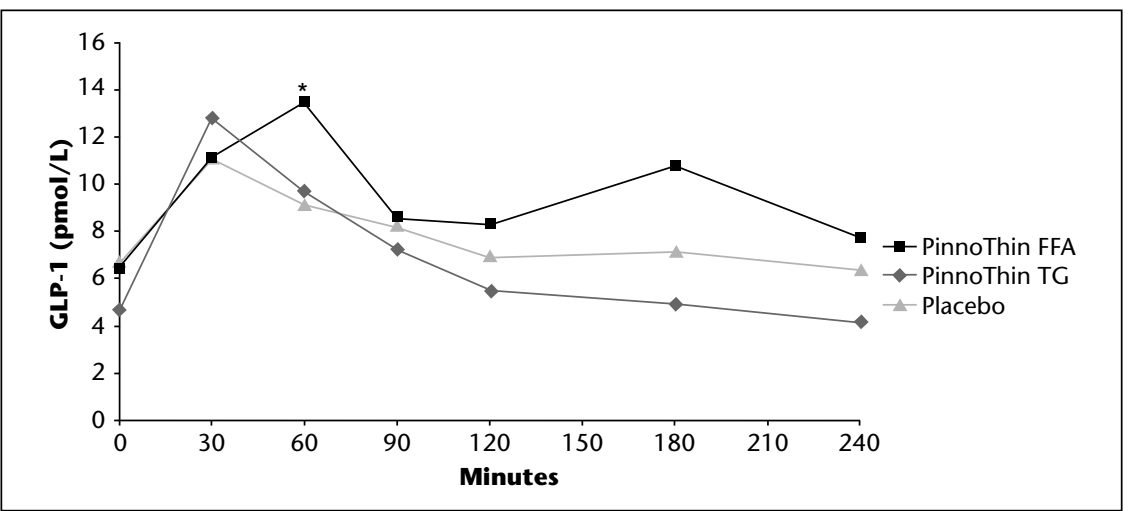

Figure 3. Four hour postprandial responses of GLP-1 in 18 overweight women. Significant differences versus placebo $(p<0.05)$ indicated by * (adapted from [28]). 
$2 \mathrm{~g}$ placebo (olive oil) in the form of capsules with water. At lunch time, the volunteers received an ad libitum buffet meal (containing highand low-fat foods, both sweet and savoury). The amount of food consumed was noted by the difference in weight of the food plate preand post-lunch to the nearest $0.1 \mathrm{~g}$. In the evening, they received an ad libitum supper, consisting of a pasta meal with ice cream dessert, which was subsequently weighed. During the entire study day, subjective measures of appetite and feeding behaviour were quantified using VAS scores. Each volunteer completed all three interventions (PinnoThin ${ }^{\text {TM }}$ FFA, PinnoThin ${ }^{\text {TM }}$ TG and placebo) with 1 week wash-out in-between.

The study results found a statistically significant lower food intake (9\%) during lunch after PinnoThin ${ }^{\mathrm{TM}}$ FFA intake compared to the placebo $(p<0.05)$. There was also a trend for reduction in energy intake with PinnoThin ${ }^{\mathrm{TM}}$ FFA, 7\% $(p<0.1)$. There was no difference in food and energy intake between the groups for the supper, indicating that the volunteers in the PinnoThin ${ }^{\mathrm{TM}}$ FFA group did not overcompensate for the reduced lunch food and caloric intake at supper. These differences found for PinnoThin $^{\text {TM }}$ FFA were not observed for PinnoThin ${ }^{T M}$ TG. No effects were seen on subjective measures of appetite and feeding behaviour after PinnoThin ${ }^{\text {TM }}$ FFA or TG intake.

Previous studies have shown that PinnoThin ${ }^{\mathrm{TM}}$ TC is digested to FFA, like similar dietary TC [31]. Furthermore, in the previous PinnoThin ${ }^{\mathrm{TM}}$ trial [28], the effects of CCK response took longer to develop for TG (60 minutes) compared to the FFA (30 minutes). Consequently, insufficient time had passed between the intake of the TC capsules and the ad libitum lunch for lipase action to convert sufficient TG to FFA. Adequate TG hydrolysis is necessary for induction of CCK release $[8,13,14]$. In addition, uptake of fat from capsules could have been further delayed since there was no simultaneous food ingestion [32]. Therefore, the differential results seen in the case of PinnoThin ${ }^{\mathrm{TM}}$ FFA and TG are anticipated.

In conclusion, this study showed that PinnoThin ${ }^{\mathrm{TM}}$ FFA directly reduces food intake, without compensation during the subsequent meal. The reduction in daily food intake observed with PinnoThin ${ }^{\mathrm{TM}}$ FFA, which corresponded to about $50 \mathrm{kcal}$, is biologically relevant. This type of reduction on a daily basis could counteract a yearly increase in body weight of 1 to $2 \mathrm{~kg}$, which in the end leads to overweight and obesity [1].

\section{Conclusion}

PinnoThin ${ }^{\mathrm{TM}}$ TG and FFA have been shown to increase satiety hormones, CCK and GLP-1 and affect subjective appetite sensation scores. Since CCK and GLP-1 are valid biomarkers of satiety and increased levels of these hormones have been associated with reduced food intake, PinnoThin ${ }^{\mathrm{TM}}$ TG and FFA may be effective in suppressing appetite and a useful tool for weight management

Acknowledgements. Many thanks to the investigators involved in the trials described herein and to all the study volunteers.

\section{REFERENCES}

1. BROWN W], WILLIAMS L, FORD JH, BALL K, DOBSONAJ. Identifying the energy gap: Magnitude and determinants of 5-year weight gain in mid-age women. Obes Res $2005 ; 13$ : 1431-41.

2. WYNNE K, STANLEYS, MCGOWAN B, BLOOM S. Appetite control. / Endocrinol 2005 ; $84: 291-318$

3. DE GRAAF C, BLOM WA, SMEETS PA, STAFLEU A, HENDRIKS HF. Biomarkers of satiation and satiety. Am / Clin Nutr 2004 ; 79 : 946-61.

4. DEGEN L, MATZINGER D, DREWE J, BEGLINGER C. The effect of cholecystokinin in controlling appetite and food intake in humans. Peptides $2001 ; 22$ : 1265-9.

5. MCLAUGHLIN J, GRAZIA LUCA M, JONES MN D'AMATO M, DOCKRAY G], THOMPSON DG. Fatty acid chain length determines cholecystokinin secretion and effect on human gastric motility. Gastroenterology $1999 ; 116$ : 46-53.

6. FELTRIN KL, LITTLE T], MEYER JH, ET AL. Effects of intraduodenal fatty acids on appetite, antropyloroduodenal motility, and plasma CCK and GLP-1 in humans vary with their chain length. Am I Physiol Regul Integr Comp Physiol 2004 ; 287 : R524-R533.

7. LAWTON CL, DELARGY HJ, BROCKMAN J, SMITH FC, BLUNDELL JE. The degree of saturation of fatty acids influences post-ingestive satiety. Br J Nutr $2000 ; 83$ : 473-82.

8. HILDEBRAND P, PETRIG C, BURCKHARDT B, ET AL. Hydrolysis of dietary fat by pancreatic lipase stimulates cholecystokinin release. Gastroenterology 1998 ; 114 : 123-9.

9. DEGEN L. Gastrointestinal motility--physiology and methods of measurement. Ther Umsch 2007 ; 64 : 195-9.

10. FRENCH S], CONLON CA, MUTUMA ST, ET AL. The effects of intestinal infusion of long-chain fatty acids on food intake in humans. Gastroenterology $2000 ; 119$ : 943-8.

11. LITTLE T], HOROWITZ M, FEINLE-BISSET C. Role of cholecystokinin in appetite control and body weight regulation. Obes Rev $2005 ; 6$ : 297-306.
12. LAL S, MCLAUGHLIN J, BARLOW I, ET AL. Cholecystokinin pathways modulate sensations induced by gastric distension in humans. Am J Physiol Gastrointest Liver Physiol 2004 ; 287 : G72-G79.

13. MATZINGER D, DEGEN L, DREWE I, ET AL. The role of long chain fatty acids in regulating food intake and cholecystokinin release in humans. Gut $2000 ; 46: 688-93$.

14. BEGLINGER C, DEGEN L. Fat in the intestine as a regulator of appetite--role of CCK. Physiol Behav $2004 ; 83$ : 617-21.

15. MUURAHAINEN NE, KISSILEFF HR, LACHAUSSEE J, PI-SUNYER FX. Effect of a soup preload on reduction of food intake by cholecystokinin in humans. Am / Physiol 1991 ; 260 : R672R680.

16. GEARY N, KISSILEFF HR, PI-SUNYER FX, HINTON V. Individual, but not simultaneous, glucagon and cholecystokinin infusions inhibit feeding in men. Am / Physiol $1992 ; 262$ : R975R980.

17. MELTON PM, KISSILEFF HR, PI-SUNYER FX. Cholecystokinin (CCK-8) affects gastric pressure and ratings of hunger and fullness in women. Am / Physiol 1992 ; 263 : R452-R456.

18. GREENOUGHA, COLE G, LEWIS I, LOCKTON A, BLUNDELL J. Untangling the effects of hunger, anxiety, and nausea on energy intake during intravenous cholecystokinin octapeptide (CCK-8) infusion. Physiol Behav 1998 ; 65 : 303-10.

19. GUTZWILLER JP, DREWE J, KETTERER S, HILDEBRAND P, KRAUTHEIM A, BEGLINGER C. Interaction between $C C K$ and a preload on reduction of food intake is mediated by CCK-A receptors in humans. Am / Physiol Regul Integr Comp Physiol 2000 ; 279 : R189-R195.

20. KISSILEFF HR, CARRETTA JC, GELIEBTERA, PI-SUNYER FX. Cholecystokinin and stomach distension combine to reduce food intake in humans. Am I Physiol Regul Integr Comp Physiol 2003 ; 285 : R992-R998.

21. MCLAUGHLIN CL, BAILE CA, BUONOMO FC. Effect of CCK antibodies on food intake and weight gain in zucker rats. Physiol Behav 1985 ; $34: 277-82$.

22. MEEREIS-SCHWANKE K, KLONOWSKI-STUMPE H, HERBERG L, NIEDERAU C. Long-term effects of CCK-agonist and -antagonist on food intake and body weight in zucker lean and obese rats. Peptides $1998 ; 19: 291-9$.

23. VERDICH C, FLINT A, GUTZWILLER JP, ET AL. A meta-analysis of the effect of glucagon-like peptide-1 (7-36) amide on ad libitum energy intake in humans. / Clin Endocrinol Metab 2001 ; 86 : 4382-9.

24. MEIER J], GALLWITZ B, SCHMIDT WE, NAUCK MA. Glucagon-like peptide 1 as a regulator of 
food intake and body weight : Therapeutic perspectives. Eur / Pharmacol $2002 ; 440$ : 269-79.

25. FLINT A, RABEN A, ASTRUP A, HOLST J). Glucagon-like peptide 1 promotes satiety and suppresses energy intake in humans. I Clin Invest 1998 ; 101 : 515-20.

26. STRADER AD, WOODS SC. Gastrointestinal hormones and food intake. Gastroenterology $2005 ; 128$ : 175-91.
27. RAYBOULD HE. Nutrient tasting and signaling mechanisms in the gut. I. sensing of lipid by the intestinal mucosa. Am / Physiol 1999; 277 : G751-G755.

28. PASMAN W], HEIMERIKX I, RUBINGH CM, ET AL. The effect of Korean pine nut oil on in vitro CCK release, on appetite sensations and on gut hormones in post-menopausal overweight women. Lipids Health Dis 2008 ; 7 : 10.
29. LIDDLE RA. Cholecystokinin cells. Annu Rev Physiol 1997 ; 59 : 221-42.

30. HUGHES GM, BOYLAND EJ, WILLIAMS NJ, ET AL. The effect of Korean pine nut oil (PinnoThin) on food intake, feeding behaviour and appetite: A double-blind placebo-controlled trial. Lipids Health Dis $2008 ; 7: 6$.

31. LIPID NUTRITION. Unpublished data. 2007.

32. HAVENAAR R. Personal communication. 2008. 